\title{
ANALISA PENGARUH MEDAN MAGNET PADA AIR FUEL RATIO PEMBAKARAN PREMIXIED CAMPURAN MINYAK KELAPA DAN MINYAK JARAK B50 TERHADAP KARATERISTIK NYALA API
}

\author{
Muhammad Asroru Maulana \\ Teknik Mesin, Fakultas Teknik \\ Universitas Maarif Hasyim Latif, Sidoarjo, Indonesia \\ e-mail : m-asroru-maulana@student.umaha.ac.id
}

\begin{abstract}
ABSTRAK
Bahan bakar hasil tambang yang dipakai semakin berkurang karena kebutuhan manusia secara terus menerus.. Sehingga kita membutuhkan sumber daya baru untuk pengganti bahan bakar fosil yaitu minyak nabati. Salah satu minyak nabati tersebut ialah minyak kelapa dan minyak jarak. Minyak kelapa dapat dimanfaatkan menjadi bahan bakar. namun bila digunakan secara langsung mempunyai kelemahan seperti viskositas tinggi, volatilitas rendah reaktivits rantai hidrokarbon tak jenuh, perlu pemanasan awal, aliran atomasi dan emisi partikel. Sedangkan minyak jarak memiliki keunggulan yaitu nilai kalor tinggi, kandungan sulfur rendah, gugus aromatik rendah dan kemampuan terurai tinggi pada lingkungan. Metode penelitian secara eksperimental dengan memanaskan minyak kelapa yang diblending dengan minyak jarak B50 hingga berbentuk uap, kemudian disalurkan ke burner yang nantinya akan diberikan udara yang dikontrol massa alirnya. Kemudian api dinyalakan dan massa alir udara dinaikkan hingga api terjadi lift off hingga blow off. Dua buah magnet diletakkan diantara burner dengan memvariasikan arah medan magnet $\mathrm{N}-\mathrm{S}, \mathrm{N}-\mathrm{N}$ dan Hasil penelitian ini bentuk dari nyala api. nyala api yang dihasilkan semakin transparan, jernih dan nyala api nampak. Arah medan magnet N-S menyebabkan temperatur yang diperoleh semakin tinggi dibandingkan arah medan magnet N-N. Tinggi rendah nyala api dipengaruhi oleh arah medan magnet semakin kuat medan magnet N-S.
\end{abstract}

Kata kunci: Air fuel ratio, arah medan magnet, minyak kelapa blending b50, minyak jarak

\section{PENDAHULUAN}

Dalam perkembangan teknologi terkini metode pembakaran premix burners dapat diaplikasikan pada peralatan dengan fluida gas. Utamanya untuk merespon regulasi emisi gas hasil pembakaran. Emisi dari nitrogen oksida (NOx) pada kondisi tertentu dapat dikurangi ketika sistem pembakaran konvensional digantikan oleh sistem premix. proses pembakaran adalah topik yang mengedepankan tentang efisiensi energi, peningkatan nilai ekonomis, dan penigkatan ekologi.

Dari beberapa metode pengontrolan pembakaran, pemakaian medan magnet adalah salah satu yang cukup menjanjikan. Dari interaksi medan magnet dengan pembakaran yaitu Gaya lorentz yang bekerja pada partikel bermuatan. Efek langsung dari medan magnet terhadap reaksi kimia. Dan Efek tidak langsung gradien magnet terhadap oksigen.

Minyak nabati adalah minyak yang disari atau diekstrak dari berbagai tumbuhan. Minyak nabati ini dapat digunakan sebagai pelumas dan bahan bakar. Salah satunya yaitu minyak kelapa dan minyak jarak Minyak kelapa dapat dimanfaatkan menjadi bahan bakar. namun bila digunakan secara langsung mempunyai kelemahan seperti viskositas tinggi, volatilitas rendah reaktivits rantai hidrokarbon tak jenuh, perlu pemanasan awal, aliran atomasi dan emisi partikel.

Sedangkan minyak jarak (rinicius communis). Minyak jarak memiliki keunggulan yaitu nilai kalor tinggi, kandungan sulfur rendah, gugus aromatik rendah dan kemampuan terurai tinggi pada lingkungan.Namun viskositas minyak jarak pagar lebih tinggi daripada solar karena memiliki rantai hidrokarbon panjang dan kandungan trigliserida tak jenuh. Dengan viskositas tinggi, minyak jarak pagar tidak dapat diaplikasikan secara langsung pada mesin diesel karena akan menyebabkan atomisasi bahan bakar rendah, pencampuran tidak sempurna, dan terjadinya deposit karbon pada katup dan injektor

Berdasarkan latar belakang diatas, perlu dilakukan penelitian untuk memperbaiki kelemahan yang dimiliki oleh minyak nabati, khususnya minyak kelapa dan minyak jarak. Salah satu cara adalah mencoba mencampurkan minyak kelapa dengan minyak jarak Dan mencari pengaruh dari penggunaan medan magnet yang diletakkan pada api pembakaran premix.

(Mizushima, Akaoka, \& Nishida 2005)melakukan penelitian tentang pengaruh medan magnet terhadap karakteristik api mikro 
difusi. Hasil dari penelitian ini adalah aplikasi medan magnet dapat mempengaruhi struktur api, panjang api juga berkurang seiring berkurangnya gradient medan magnet secara vertikal. Pada kondisi yang sama temperatur nyala api meningkat. Aplikasi dari gradien medan magnet mengindikasikan bahwa medan magnet dapat meng-induksi oksigen dan juga dapat dijadikan sebagai kontrol pembakaran.

((B.N. Riwu, Wardana, \& Yuliati, 2016) analisis pengaruh variasi medan magnet terhadap karateristik nyala api difusi dengan bahan bakar lpg penelitian ini menghasilkan peningkatan laju aliran LPG akan meningkatkan tinggi nyala api dan luas nyala api. Namun peningkatan laju aliran udara akan mengurangi luas nyala api dan tinggi nyala api

\section{METODE PENELITIAN}

Metode penelitian yang dilaksanakan ini dengan metode pembakaran premix pada bunsen burner dengan pencampuran minyak kelapa dengan minyak jarak B50 yang dipengaruhi oleh medan magnet tolak menolak dan medan magnet tarik menarik. Penelitian ini dilakukan dengan cara pengamatan langsung untuk mendapatkan data yang secara nyata. Obyek yang akan diteliti diambil datanya pada tahapan tertentu menghasilkan beberapa data yang dapat diperbandingkan. Hasil data tersebut disajikan baik dalam bentuk grafik maupun uraian. Dengan cara ini akan diuji pengaruh dari air fuel ratio terhadap bentuk nyala api,tinggi nyala api, temperatur dan kecepatan laminer. Skema penelitian ini ditunjukan pada gambar 1.

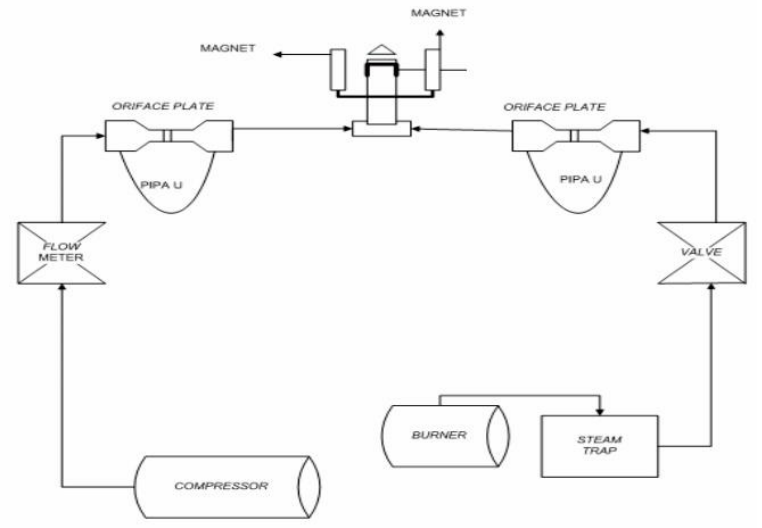

Gambar 1. Skema penelitian

Bunsen digunakan untuk memanaskan bahan bakar minyak tersebut pada suhu $350^{\circ}$ untuk menghasilkan uap lalu dialirkan menuju oriface plate yang menimbulkan tekanan $\Delta \mathrm{h}$ bahan bakar sebesar $1 \mathrm{~mm}$. Uap tersebut akan menuju ke burner kemudian uap dibakar dengan memvariasikan udara dialirkan dari kompresor dengan setiap penambahan tekanan udara pada flowmeter sebesar $2 \mathrm{~mm}$ pada pipa u. Data gambar tersebut didapat dari proses pembakaran mulai dari nyala api difusi sampai dengan nyala api padam yang direkam menggunakan kamera.

\section{HASIL DAN PEMBAHASAN}

Bahan bakaryang digunakan minyak kelapa yang diblending dengan minyak jarak b50 yang dipanaskan hingga temperatur $350^{\circ}$.

Spesifikasi bahan bakar sebagai berikut:

1. Densitas $\rho$ bahan bakar $=0,00025$ gram $/$ $\mathrm{cm} 3$

2. AFR minyak kelapa blending minyak jarak b50= 6,62

Rumus perhitungan air fuel ratio

1. $\mathrm{AFR}=\frac{\dot{\mathrm{m}}_{\text {udara }}}{\dot{\mathrm{m}}_{\text {bahan bakar }}}$

Hubungan air fuel ratio terhadap bentuk nyala api tanpa medan magnet

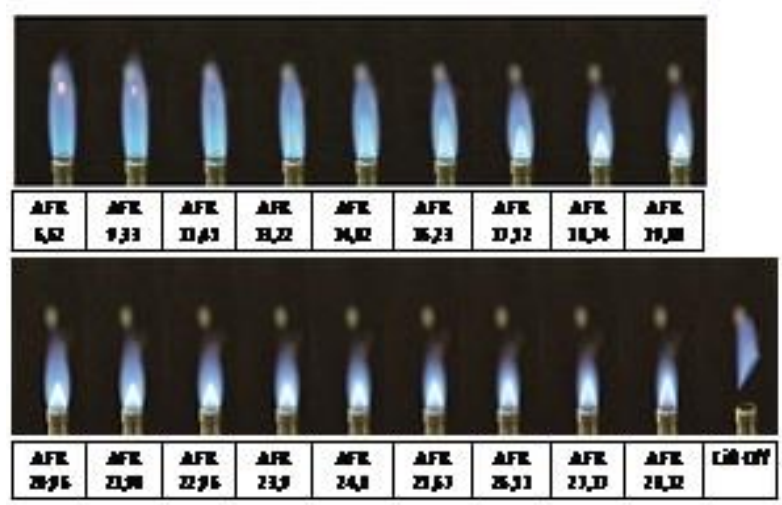

Gambar 2. Hubungan air fuel ratio terhadap bentuk nyala api minyak nabati B50 tanpa medan magnet

Gambar 2. merupakan hubungan air fuel ratio terhadap nyala api tanpa medan magnet, pada saat awal nyala api warna kuning dari api merupakan bahan bakar yang belum terbakar dengan sempurna dan akan perlahan berkurang dan hilang setiap udara flowmeter ditambah. kemudian sudut segitiga api dalam mulai terbentuk pada afr 17,52 namun belum sempurna berbentuk lancip. Warna sudut nyala api terbentuk segitiga warna biru agak putih lebih mendominan api. Pada saat udara flowmeter ditambah tinggi sudut akan semakin meningkat dan tinggi api menjadi lebih pendek hingga nyala api lift off.

Hubungan air fuel ratio terhadap bentuk nyala api medan magnet tolak

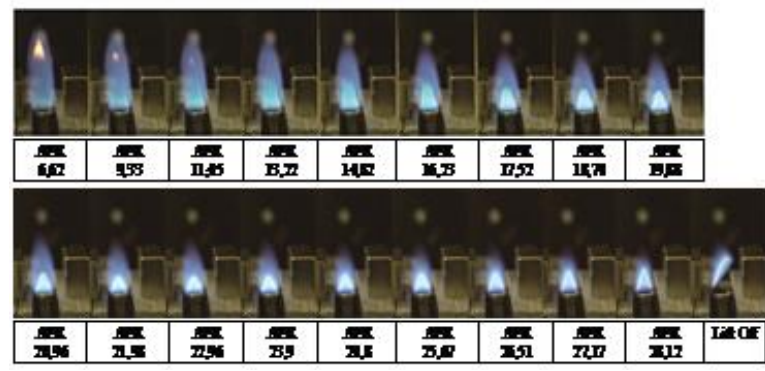

Gambar 3. Hubungan air fuel ratio terhadap bentuk nyala api minyak nabati B50 medan magnet tolak 
Gambar 3. merupakan hubungan air fuel ratio terhadap nyala api medan magnet tolak menolak, pada saat awal nyala api warna kuning dari api merupakan bahan bakar yang belum terbakar dengan sempurna dan akan perlahan berkurang dan hilang setiap udara flowmeter ditambah. kemudian sudut segitiga api dalam mulai terbentuk pada afr 17,52 namun belum sempurna berbentuk lancip. Warna sudut nyala api terbentuk segitiga warna biru agak putih lebih mendominan api. Pada saat udara flowmeter ditambah tinggi sudut akan semakin meningkat dan tinggi api menjadi lebih pendek hingga nyala api lift off.

\section{Hubungan air fuel ratio terhadap bentuk nyala api medan magnet tarik}

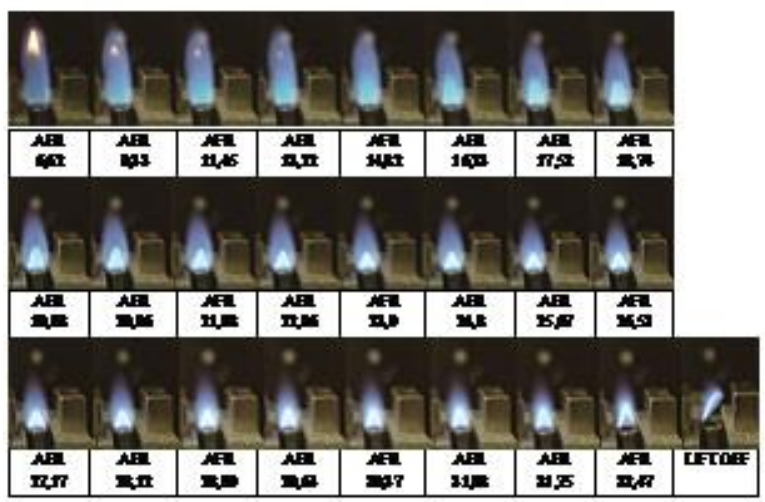

Gambar 4. Hubungan air fuel ratio terhadap bentuk nyala api minyak nabati B50 medan magnet tarik.

Gambar 4. merupakan hubungan air fuel ratio terhadap nyala api medan magnet tarik menarik pada saat awal nyala api terlihat warna kuning dari api merupakan bahan bakar yang belum terbakar dengan sempurna dan akan perlahan berkurang dan hilang setiap udara flowmeter ditambah. kemudian sudut segitiga api dalam mulai terbentuk pada afr 18,74 namun belum sempurna berbentuk lancip. Warna sudut nyala api terbentuk segitiga warna biru agak putih lebih mendominan api. Pada saat udara flowmeter ditambah tinggi sudut akan semakin meningkat dan tinggi api menjadi lebih pendek hingga nyala api lift off. Dibandingkan dengan nyala api tanpa magnet dan magnet tolak menolak, nyala api dengan menggunakan magnet tarik menarik terlihat lebih stabil dan lebih lama.

\section{Hubungan air fuel ratio terhadap tinggi nyala api}

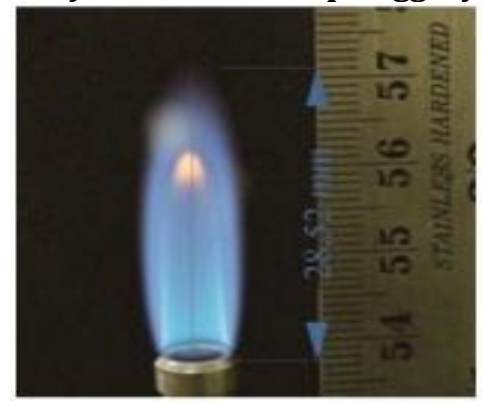

Gambar 5. Contoh gambar pengambilan tinggi api tanpa medan magnet

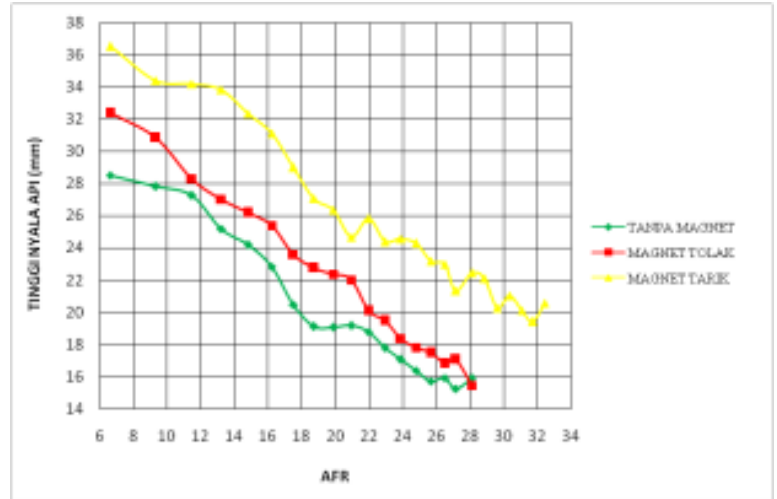

Gambar 6. Grafik hubungan air fuel ratio terhadap tinggi nyala api, dengan tanpa medan magnet, medan magnet tolak, dan medan magnet tarik.

Gambar 6. merupakan grafik hubungan air fuel ratio terhadap terhadap tinggi nyala api, dengan tanpa medan magnet, medan magnet tolak, dan medan magnet tarik. Dari perbandingan tersebut tinggi nyala api medan magnet tarik adalah tertinggi dengan ketinggian awal 36,54 mm dibandingkan nyala api dari medan magnet tolak dengan ketinggian awal 32,37 mm dan tanpa medan magnet dengan ketinggian awal 28,52 mm.

Hubungan air fuel ratio terhadap temperatur nyala api

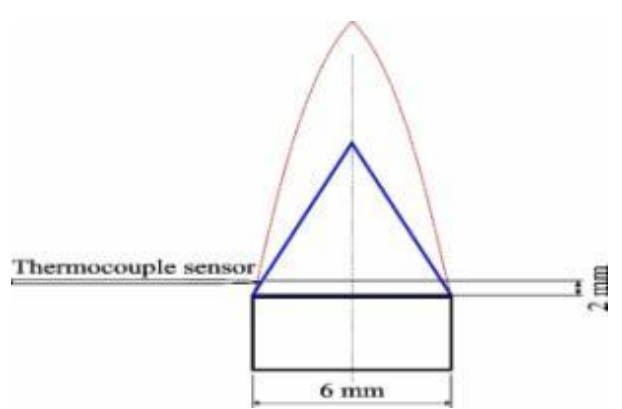

Gambar 6. Skema pengambilan temperatur nyala api Cara pengambilan temperatur nyala api yaitu setelah nyala api terbentuk, kemudian termokopel ditempatkan sekitar $2 \mathrm{~mm}$ diatas permukaan burner. Penempatan termokopel berada digaris nyala api luar. Pengukuran temperatur nyala api ini berlangsung terus menerus pada reaksi pembakaran berlangsung dengan penambahan laju aliran massa udara.

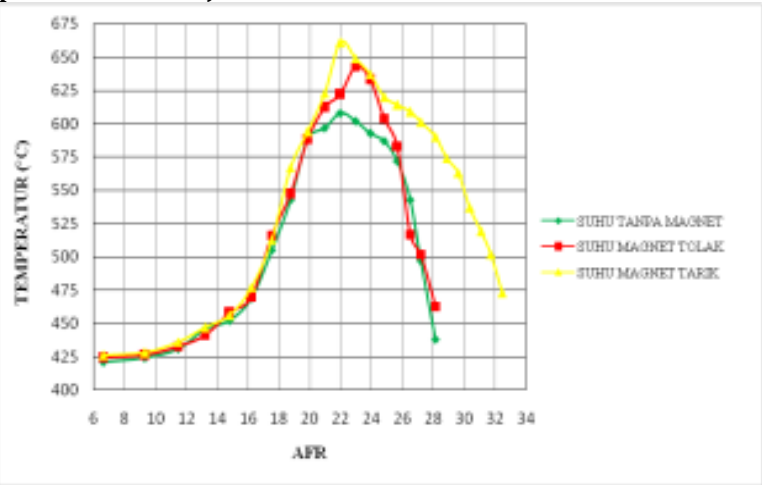

Gambar 7. Grafik hubungan air fuel ratio terhadap temperatur nyala api, dengan tanpa medan magnet, medan magnet tolak, dan medan magnet tarik. 
Gambar 7 merupakan grafik hubungan air fuel ratio terhadap temperature nyala api, dengan tanpa medan magnet, medan magnet tolak, dan medan magnet tarik. Dari perbandingan tersebut temperatur nyala api medan magnet tarik saat pada kondisi debit udara dan debit bahan bakar tercampur seimbang adalah tertinggi dengan termperatur $661^{\circ} \mathrm{C}$ dibandingkan nyala api dari medan magnet tolak dengan temperatur $643{ }^{\circ} \mathrm{C}$ dan tanpa medan magnet dengan temperatur $608^{\circ} \mathrm{C}$.

Hubungan air fuel ratio terhadap kecepatan pembakaran laminer dengan tanpa medan magnet, medan magnet tolak, dan medan magnet tarik (SL)

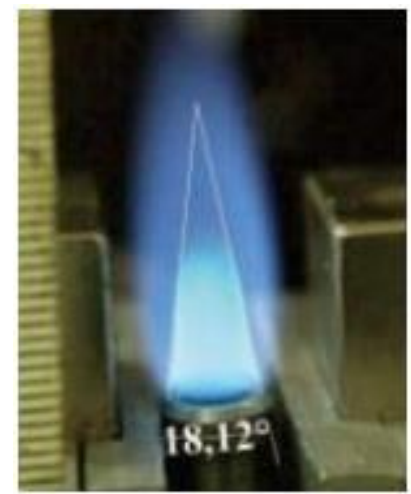

Gambar 8. Contoh Gambar Sudut Nyala Api

didapatkan kecepatan api laminer pada metode bunsen burner dapat dihitung dengan persamaan:
SL $\quad=$ Vx Sin $\alpha$
$\mathrm{SL} \quad=$ kecepatan api laminer $(\mathrm{cm} / \mathrm{s}) \mathrm{v}$
$\mathrm{V}=$ kecepatan reaktan $(\mathrm{cm} / \mathrm{s}) \alpha$
$\operatorname{Sin} \alpha=$ sudut api yang terbentuk $\left({ }^{\circ}\right)$

Nilai dari kecepatan reaktan sendiri dapat ditentukan dengan persamaan:

$$
\mathrm{V}=\frac{\text { QBahanBakar }+ \text { QUdara }}{\Delta \text { Burner }}
$$

Keterangan :

$\mathrm{Q}$ bahan bakar = debit aliran bahan bakar $(\mathrm{cm} 3 / \mathrm{s})$

$\mathrm{Q}$ udara $\quad=$ debit aliran udara $(\mathrm{cm} 3 / \mathrm{s})$

$\mathrm{Ab} \quad=$ luas bagian melintang burner

(cm2)

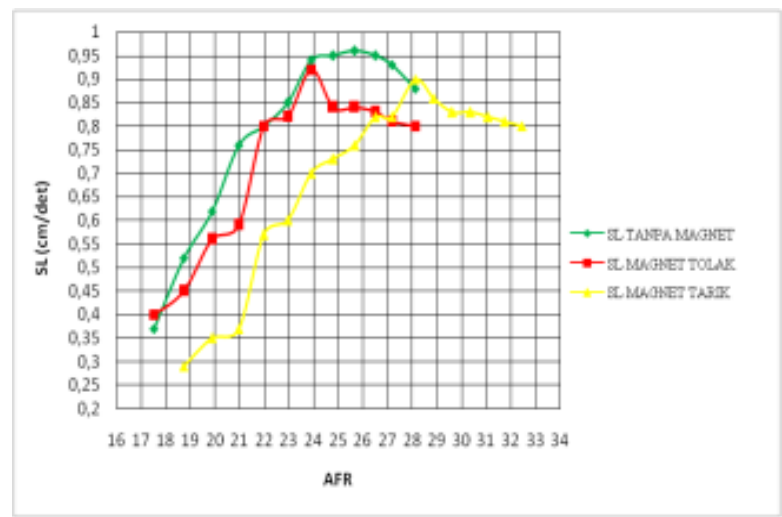

Gambar 9. Grafik hubungan air fuel ratio terhadap kecepatan pembakaran laminer, dengan tanpa medan magnet, medan magnet tolak, dan medan magnet tarik.

Gambar 9 merupakan grafik hubungan air fuel ratio terhadap kecepatan pembakaran laminer, dengan tanpa medan magnet, medan magnet tolak, dan medan magnet tarik. Dari perbandingan tersebut kecepatan pembakaran laminer S_L terhadap air fuel ratio dengan tanpa magnet adalah tertinggi dengan $0,96 \mathrm{~cm} / \mathrm{s}$, dibandingkan dengan magnet tolak $0,92 \mathrm{~cm} / \mathrm{s}$ dan magnet tarik $0,90 \mathrm{~cm} / \mathrm{s}$.

\section{PENUTUP}

Dari hasil dan analisa pengaruh medan magnet terhadap air fuel ratio pembakaran premixied campuran minyak kelapa dan minyak jarak B50 terhadap karateristik nyala api dapat disimpulkan sebagai berikut.

1. Medan magnet dapat mempengaruhi kecepatan pembakaran api premixed minyak minyak kelapa dan minyak jarak B50 dimana nyala api pembakaran lebih lama daripada tanpa pengaruh medan magnet

2. Medan magnet dapat mempengaruhi ketinggian nyala api minyak kelapa dan minyak jarak B50 dimana tinggi api pembakaran lebih tinggi daripada tanpa pengaruh medan magnet, dan tinggi nyala api tertinggi saat dipengaruhi magnet tarik

3. Medan magnet dapat mempengaruhi temperatur nyala api minyak kelapa dan minyak jarak B50, dimana temperatur nyala api lebih tinggi daripada tanpa pengaruh medan magnet, dan temperatur tertinggi saat dipengaruhi medan magnet tarik.

4. Medan magnet dapat mempengaruhi kecepatan pembakaran laminer S_L minyak kelapa dan minyak jarak B50, dimana kecepatan pembakaran laminer S_L lebih kecil daripada dengan tanpa pengaruh medan magnet. Dan kecepatan pembakaran laminer terkecil adalah dengan pengaruh medan magnet tarik.

\section{UCAPAN TERIMA KASIH}

Secara khusus saya ucapkan banyak terima kasih kepada dosen pembimbing bapak dony perdana, st. Mt yang telah bersedia meluangkan waktu untuk memberikan bimbingan untuk menyelesaikan penelitian ini. Dan juga saya ucapkan banyak terima kasih kepada teman teman teknik mesin universitas maarif hasyim latif yang sudah membantu dan mensuport dalam menyelesaikan penelitian ini.

\section{DAFTAR PUSTAKA}

Afifah, Y. N. (2016). ALIRAN TAK TUNAK FLUIDA NANO MAGNETOHIDRODINAMIK ( MHD) YANG MELEWATI BOLA. 
Afifah, Y. N., \& Putra, B. C. (2018). Model Matematika Aliran Tak Tunak Pada Nano Fluid Melewati Bola Teriris Dengan Pengaruh Medan Magnet. Teknika: Engineering and Sains Journal, 2(2), 119-124.

Afifah, Y. N. (2019). Analysis of Unsteady Magneto Hydro Dynamic (MHD) Nano Fluid Flow Past A Sliced Sphere Analysis of Unsteady Magneto Hydro Dynamic ( MHD) Nano Fluid Flow Past A Sliced Sphere. IOP Conference Series: Materials Science and Engineering, 494, 012033 https://doi.org/10.1088/1757899X/494/1/012033

B.N. Riwu, D., Wardana, I. N. G., \& Yuliati, L. (2016). Kecepatan Pembakaran Premixed Campuran Minyak Jarak - Liquefied Petroleum Gas (LPG) pada Circular Tube Burner. Jurnal Rekayasa Mesin, 7(2), 41-47.

Gamayel, A. (2016). Karakteristik Fisik Bahan Bakar Alternatif Campuran Minyak Jarak (Cjo)Minyak Cengkeh (Physical Properties of Crude Jatropha Curcas Oil-Clove Oil Blend). Semesta Teknika, 19(2), 119-125.

Gunawan, E. et al. (2019) 'Analysis of the Effect of Current Flow Variations in GTAW on SS 400 Plate Material Connected with SUS 304 Stainless Steel Plate Against Tensile Strength and Hardness with ER308L Electrodes', Journal of Physics: Conference Series, 1175(1). doi: 10.1088/1742-6596/1175/1/012277.

Mizushima, Y., Akaoka, I., \& Nishida, Y. (2005). Effects of magnetic field on inflammation. Experientia, 31(12), 1411-1412. https://doi.org/10.1007/BF01923216

Perdana, D., Wardana, I. N. G., Yuliati, L., \& Hamidi, N. (2018). The role of fatty acid structure in various pure vegetable oils on flame characteristics and stability behavior for industrial furnace. Eastern-European Journal of Enterprise Technologies. https://doi.org/10.15587/17294061.2018.144243

Putra, B. C., \& Afifah, Y. N. (2018). Gaussian Mixture Model Untuk Penghitungan Tingkat. Teknika: Engineering and Sains Journal, 2, 53-58.

Yunita Nur Afifah, MNH Qomarudin and Imamatul Ummah (2020) 'Optimal Control Model Pemanenan Prey-Predator di Area Konservasi Ikan', Buana Matematika : Jurnal Ilmiah Matematika dan Pendidikan Matematika, 10(1), pp. 1-16. doi: 10.36456/buanamatematika.v10i1.2410. 